\title{
Molecular and Morphological Characteristics of Aradi Goats with Prediction Equation of Growth Pattern
}

\author{
M. F. Elzarei ${ }^{1,2}$ \& E. F. Mousa ${ }^{1,3}$ \\ ${ }^{1}$ Department of Animal Production and Breeding, College of Agriculture and Veterinary Medicine, Qassim \\ University, Qassim, Saudi Arabia \\ ${ }^{2}$ Department of Animal Production, Faculty of Agriculture, Suez Canal University, Ismailia, Egypt \\ ${ }^{3}$ Animal Production Department, Faculty of Agriculture, Assiut University, Assiut, Egyp \\ Correspondence: M. F. Elzarei, Department of Animal Production and Breeding, College of Agriculture and \\ Veterinary Medicine, Qassim University, Qassim, Saudi Arabia. E-mail: zray@qu.edu.sa
}

Received: February 15, 2017

Accepted: February 28, $2017 \quad$ Online Published: March 7, 2017

doi:10.5539/ijb.v9n2p29

URL: https://doi.org/10.5539/ijb.v9n2p29

\begin{abstract}
To specify morphological characteristics and choose preferable growth equation for kids up to 24 weeks of age, in Aradi goats, 338 kids of fathered by 25 sires and mothered by 153 does were used. Also, 74 individuals used in assisted with 29 microsatellites markers to identify molecular characterization. Results illustrated the linear equation was preferable according to easy compute, have two linear additive parameters and equation accuracy. The accuracy of that equation was very high ranged from 0.996 and 0.993 for predicted weights in male and female, respectively. Five loci showed only three alleles for each, while the rest of markers ranged from 13 alleles in loci CSRD247 and RM088 to four alleles in locus ILSTS011. The average of observed heterozygosity was 0.63 ranged 0.89 in BM2113 locus to 0.17 in ILSTS002 locus. The expected heterozygosity reached the maximum value in locus RM088 and the minimum one in locus OARE129, the average value was 0.65 . The polymorphic information content values ranged from 0.85 (RM088) to 0.22 (OARE129). Thus, the investigation on a set of 29 microsatellites revealed high degree of genetic variability in Aradi goat indicating an important indigenous genetic resource.
\end{abstract}

Keywords: Microsatellites, Heterozygosity, Polymorphic information content

\section{Introduction}

Aradi is one of the most influential native goat breed in Saudi Arabia raised mainly for meat production, wide investigations were made to improve its productivity through crossing with exotic breed such as Damascus. As known, genetic improvement of any livestock breed depends on the identification of animals capable of transmitting their desirable characteristics to their offspring. For these reasons, deepness studies concerning on growth pattern with more precise techniques are highly needed. In this matter, mathematical functions of the animal growth curve have a wide interest (Morant \& Gnanasakthy, 1989; Grossman et al., 1999; Mostert et al., 2003). Mathematical modelers seek to define parametric descriptors of growth shape. Many mathematical models have been used extensively to describe growth data in various species, Von Bertalanffy (Bertalanffy, 1957), Brody (Brody, 1945), Gompertz (Winsor, 1932), Logistic (Nelder 1961), Richards (Richards, 1959), Exponential Brody (Brody, 1945) simple and multiple regression (Leech \& Healy, 1959; Sprint, 1967; Grizzle \& Allen, 1969).

The most frequently important factors used to correct fixed effect are, season, sex, litter size at birth, age of dams, location and genetic groups. Brody (1945) used a mathematical function to describe a growth curve. As growth models are useful in growth prediction, linear equations have been used to express growth pattern at specific timer of age. Molecular characterization of any breed can be done by various methods and type of genetic markers. Microsatellites is one of the most important useful markers, intensively used in genomic variability and diversity studies (Ganai \& Yadav, 2001; Kumar et al., 2005). These microsatellite markers considered to be of great benefits in analysis of paternity or genetic variability among and within studied breeds.

The present study was established to determine both molecular and morphological characteristics in Aradi goats in addition with formulate the prediction equation of growth pattern from birth to 24 weeks of age. Results obtained from these equations are very essential in decisions of culling or retaining a Goat at an earlier stage of life. 


\section{Materials and Methods}

\subsection{Growth Pattern}

A total number of 338 kids fathered by 25 sires and mothered by 153 does belonging to Animal Experimental Farm, Qassim University, Saudi Arabia were utilized in this study. Body weights were measured at birth and every four weeks intervals thereafter up to 24 weeks of age. Linear equation with only two parameters was perfect fit to growth data on Aradi goat from birth to 24 weeks of age. The linear model $y_{t}=a+b t$ was convenient tendency of growth pattern, a biological mean of parameter $(b)$ was average growth rate and $(a)$ was initial body weight (Macciotta et al., 2011; Madalena et al., 1979; Kamidi, 2005). A total of 1533 records of Aradi kids growth weights were used to test the model. The fixed effect consider in this study were year of season which have 20 classes (4 seasons/year; five year from beginning of 2011 to the end of 2015, litter size at birth with 3 classes single, twins and triplet and sex with two classes male and female. The data was distributed through the traits shown in Table 1.

Table 1. Number of records per each trait, overall mean of the traits \pm standard deviation (S.D), least square means of male and female \pm stander error (S.E) per $\mathrm{Kg}$

\begin{tabular}{lcccc}
\hline \multirow{2}{*}{ Trait } & \multirow{2}{*}{ No. } & \multirow{2}{*}{ Mean \pm SD } & \multicolumn{2}{c}{ LSMean \pm SE } \\
\cline { 4 - 5 } & & & Male & Female \\
\hline W0 & 338 & $3.01 \pm 0.69$ & $3.36 \pm 0.06$ & $3.06 \pm 0.07$ \\
W4 & 257 & $7.03 \pm 1.74$ & $7.37 \pm 0.18$ & $6.78 \pm 0.22$ \\
W8 & 229 & $10.23 \pm 2.67$ & $10.25 \pm 0.26$ & $9.28 \pm 0.35$ \\
W12 & 224 & $13.42 \pm 3.66$ & $13.96 \pm 0.38$ & $12.34 \pm 0.47$ \\
W16 & 189 & $16.25 \pm 4.25$ & $17.10 \pm 0.53$ & $14.88 \pm 0.61$ \\
W20 & 171 & $18.32 \pm 4.07$ & $19.26 \pm 0.55$ & $16.60 \pm 0.59$ \\
W24 & 151 & $21.50 \pm 4.66$ & $23.19 \pm 0.63$ & $19.66 \pm 0.61$ \\
\hline
\end{tabular}

Model used:

$$
\mathrm{Y}_{\mathrm{ijk}}=\mu+\mathrm{YS}_{\mathrm{i}}+\mathrm{LSB}_{\mathrm{j}}+\mathrm{SX}_{\mathrm{k}}+\mathrm{e}_{\mathrm{ijkl}}
$$

Where:

$\mu=$ the overall mean,

$\mathrm{YS}_{\mathrm{i}}=$ the year season for $\mathrm{i}=1, \ldots 20$,

$\mathrm{LSB}_{\mathrm{j}}=$ the litter size effect at birth for $\mathrm{j}=1-3$,

$\mathrm{SX}_{\mathrm{k}}=$ the sex effect for $\mathrm{k}=1-2$, and

$\mathrm{e}_{\mathrm{ijkl}}=$ random error term

\subsection{Application of Linear Model}

The preliminary results of kids data showed that the linear function is preferable over the others and consequently appoint to use it. This conclusion was based on the coefficient of determination $\left(\mathrm{R}^{2}\right)$, finding biological interpretation of the estimated parameters. Hence this technique has its limitation, it is recommended to utilize for special stage intervals of growth. For the period from birth to 24 weeks of age, the linear equation fitted to the least square mean of seven continuous weights from birth (W0) and every 4 weeks according to model:

Model 1:

$$
Y_{t}=a+b t+e_{t}
$$

Where,

$\mathrm{Y}_{\mathrm{t}}=$ weight of kid at time $\mathrm{t}$,

$\mathrm{a}=$ intercept (initial body weight parameter),

$b=$ regression coefficient (rate of gain),

$\mathrm{t}=$ time in week, and

$e_{t}=$ random error term 


\subsection{Morphological Measurements}

Body weights of goat turn as outcome of some fixed effects among them, management system, pregnancy, feed, season of birth, year, stage of lactation, age of dam, type of birth, parity, sex and breed effect. These factors are less affected to linear body confirmation. Furthermore, linear measuring is relatively simple to process in compare with animal weight as indirect method (Riva et al., 2004; Adeyinka \& Mohammed, 2006)

\subsubsection{Used Measurements}

\section{Height at withers (HAW)}

Height of the withers is the distance from the peak point of the animal surface at the withers to the flat ground. It is better to use instrument made from two arms of wood, one of this arm is long vertical and other is short horizontal sliding strongly up and down on vertical centimeter scale index. The height at withers measure from shoulder at peak point by move shorter arm down until touches the shoulder.

Body length (BDL)

Length of the body is the distance from the origin of the ear to the origin of the tail. Body length can be measured also as the distance from origin of tail to beginning of the neck. Attention should be taken to ensure that the vertebral column is straight in both directions vertical and horizontal scale.

\section{Hip width $(H W)$}

Hip width is the distance between the outside edges of the hip bones on the right and left and measured with a pair of arm hinged and linked by a movable joint such as compass or caliper. One of these arms sliding on the centimeter index when released a way from the other giving distance between the two points.

\subsection{Molecular Characterization}

Seventy-four unrelated animals selected from accredited and commercial farms representing various regions of Saudi Arabia which raised Aradi breed were used in this study. Blood samples collected from the animals kept in Ice-tank using EDTA as anticoagulant. Then, DNA extraction began using ILLUSTRA blood mini spin kit (GE Life Sciences). After that, DNA samples were taking to determine the quantity and quality of DNA using Thermo NanoDrop 8000 UV-Vis Spectrophotometers. Twenty-nine selected microsatellites markers as shown in table 2 were used to study the molecular aspects in this way. Table 2 also showed characteristics for microsatellite markers reported for genetic variability analysis.

Markers were amplified using ProFlex ${ }^{\mathrm{TM}}$ PCR System Applied Biosystems. The PCR protocol are shown in table 3and PCR program shown in Figure 1.

Annealing temperature ranged from 55 up to 58 depending on primers sequence.

After PCR finished a vertical 8\% polyacrylamide gel used in belong with 50bp DNA ladder to estimate allele sizes in base pairs (bp). A reference animal used to compare and correct allelic size in each gel.

\subsection{Genetic Markers Polymorphism}

To estimate the genetic variation, the following parameters were used: number of alleles, expected heterozygosity (He) and observed heterozygosity (Ho), calculated by Genetix 4.05 of Belkhir et al., 2004. Polymorphic information content (PIC) was calculated using program provide by Nagy et al. (2012).

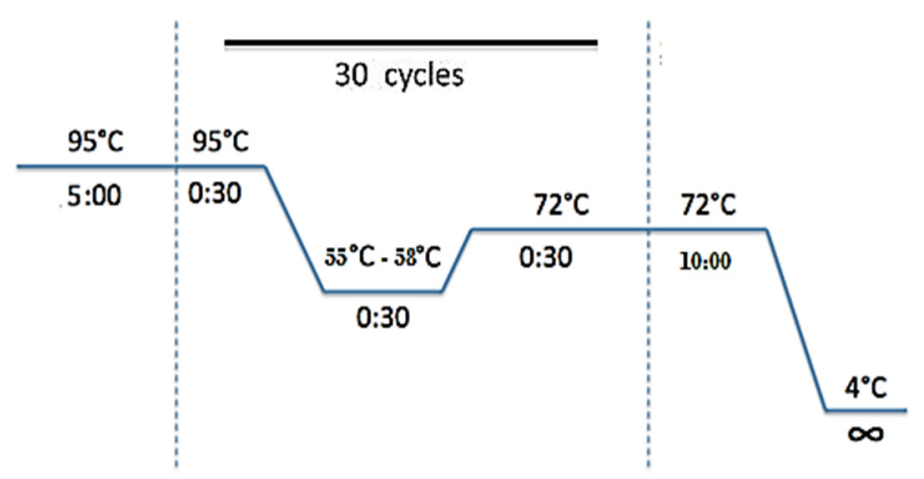

Figure 1. PCR program used to amplify each marker 
Table 2. Characteristics* for 29 microsatellite markers reported for genetic variability analysis

\begin{tabular}{|c|c|c|c|c|}
\hline Locus & $\mathbf{H}_{\mathbf{0}}$ & $\mathbf{H}_{\mathrm{e}}$ & Allelic Number & Size Range \\
\hline INRA005 & 0.63 & 0.63 & 6 & $113-121$ \\
\hline RM088 & 0.44 & 0.88 & 17 & $109-147$ \\
\hline ILSTS002 & 0.70 & 0.82 & 12 & $113-135$ \\
\hline CSRD247 & 0.69 & 0.76 & 11 & $220-248$ \\
\hline INRA023 & 0.75 & 0.81 & 10 & $195-213$ \\
\hline SRCRSP5 & 0.71 & 0.78 & 12 & $160-182$ \\
\hline ILSTS011 & 0.75 & 0.77 & 9 & $264-280$ \\
\hline MAF70 & 0.69 & 0.80 & 13 & $138-166$ \\
\hline TGLA53 & 0.73 & 0.75 & 13 & $137-161$ \\
\hline SRCRSP8 & 0.77 & 0.81 & 14 & $212-242$ \\
\hline SRCRSP09 & 0.77 & 0.79 & 13 & $115-143$ \\
\hline ILSTS044 & 0.35 & 0.52 & 8 & $142-177$ \\
\hline OarAE129 & 0.83 & 0.74 & 9 & $130-175$ \\
\hline ILSTS019 & 0.77 & 0.82 & 9 & $142-162$ \\
\hline ILSTS033 & 0.49 & 0.75 & 12 & $151-187$ \\
\hline ILSTS005 & 0.20 & 0.63 & 7 & $174-190$ \\
\hline ILSTS058 & 0.71 & 0.94 & 23 & $136-188$ \\
\hline ILSTS087 & 0.42 & 0.89 & 13 & $142-164$ \\
\hline ILSTS034 & 0.25 & 0.39 & 6 & $153-185$ \\
\hline ILSTS029 & 0.86 & 0.83 & 14 & 148-191 \\
\hline ILSTS049 & 0.44 & 0.71 & 9 & $160-184$ \\
\hline ILSTS030 & 0.78 & 0.84 & 9 & $159-179$ \\
\hline ILSTS082 & 0.98 & 0.84 & 15 & $100-136$ \\
\hline ILSTS022 & 0.38 & 0.49 & 6 & $189-225$ \\
\hline OARFCB48 & 0.80 & 0.82 & 11 & $149-181$ \\
\hline SRCRSP1 & 0.85 & 0.70 & 13 & $113-143$ \\
\hline OARCP34 & 0.86 & 0.71 & 13 & $102-132$ \\
\hline BM2113 & 0.88 & 0.79 & 19 & $120-165$ \\
\hline BM1818 & 0.77 & 0.79 & 10 & $253-272$ \\
\hline
\end{tabular}

*Data obtained from, Araújo et al. (2006); Dixit et al. (2010); Hoda et al. (2011); Kumar et al. (2009); Li et al. (2002); Seilsuth et al. (2016).

Table 3. PCR protocol

\begin{tabular}{ll}
\hline Components & volume \\
\hline Genomic DNA (20ng), & $2 \mu 1$ \\
PCR Master mix (applied Biosystems) & $5 \mu 1$ \\
primer mix (50 pmoles) & $0.4 \mu 1$ \\
DNase free water & $2.6 \mu 1$ \\
Total Volume & $10 \mu 1$ \\
\hline
\end{tabular}

\section{Results and Discussion}

\subsection{Factors Effecting Weights}

As shown in table 4 , all fixed effects under study showed highly significant $(\mathrm{P}<0.01)$ in all 7 weights from birth to 24 weeks. These results were in agremment with that found by Khalil et al., 2010 and Mousa et al. (2013b).

\subsection{Linear Model}

The linear model was applied on male and female separately. The $\mathrm{R}^{2}$ of that model was 0.996 and 0.993 in male and female, respectively. Table 4 show the Intercept $a$ (initial body weight) and regression coefficient $b$ (growth rate /per week) from regression analysis of weight in $\mathrm{kg}$ on time per (week) for male and female.

As shown in table 5, illustrate that the biological mean of intercept $a$, was the initial body weight (birth weight), were $3.84 \mathrm{Kg}$ and $3.76 \mathrm{Kg}$ for male and female, respectively. The biological mean of the $\mathrm{b}$ was growth rate, were 0.80 and $0.67 \mathrm{Kg}$ /week for male and female, respectively. These results were close to (Mousa et al., 2013a) using parabola model on the same breed. 
Figure 2 showed the observed values of the weight versus the predicted value from the linear equation. The predicted values of linear equation were slightly overestimated than observed in the initial body weight and weights from 20-24 weeks and slightly underestimate from 12-16 weeks in male and female. The correlation between true value of weights and predicted value were 0.998 and 0.996 male and female, respectively. The mean of square due to regression was highly significant $(\mathrm{P}<0.01)$ in male and female. To change the growth pattern to the best, run this equation for individually to get $a$ and $b$ for each animal and after that make a selection for the animal which have more than $3.84 \mathrm{~kg}$ as initial or more than $800 \mathrm{~g} /$ week as growth rate in week or both of them in male and by the same way in female.

Estimate of linear parameters in table 5 illustrate that the change in $\mathrm{t}$ (age of kid) by unite will be following by change in y (weight) by $800 \mathrm{~g} /$ week in male. This, mean that average daily growth rate was $114.28 \mathrm{~g}$ in male. Of course, the growth rate of kids is lower than lambs when comparing each other by the same age. But, the growth rate of Aradi goat is more than Sudanese Goat kids goat $87 \mathrm{~g} /$ day (Wilson, 1976) and East African goat 91g/day (Wilson, 1958). By the same way, the average growth rate in a week was $670 \mathrm{~g}(95.71 \mathrm{~g} /$ day $)$ in female.

In General, the average growth rate for male and female kids were rapid or slow this according to the stage of age. The growth rate goes rapidly from birth to weaning weight showing straight line shape and start to decrease in growth rate as long as kids grows up in a lifetime showing curve linear shape (Mousa et al., 2010, 1989). The pattern of growth at this time it turns into a curved shape growth instead of linear shape.

The linear equation for predicting weights will be:

In male:

$$
\widehat{y}=3.84+0.800 t
$$

In female:

$$
\widehat{y}=3.76+0.670 t
$$

By substitute (t) at any time, will be obtain the predicted weight at this time.

Table 4. The significance effect of fixed factors year of season (Ys), litter size (LSB) and sex (sex) on all weights

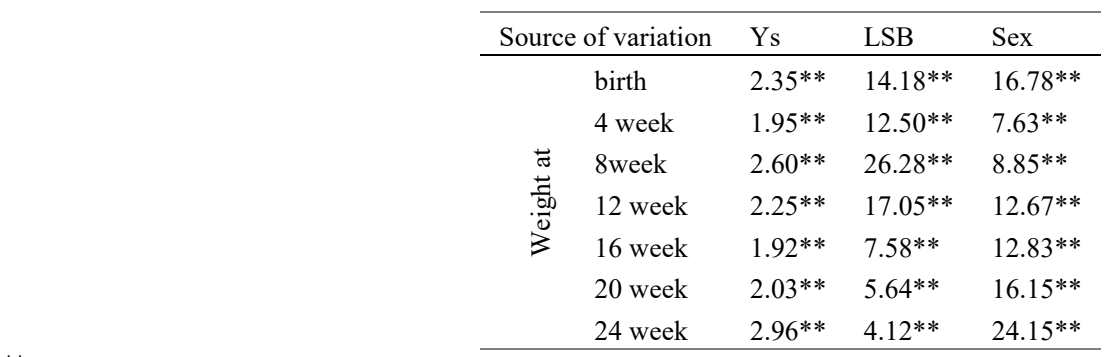

${ }^{* *}(\mathrm{p}<0.01)$.

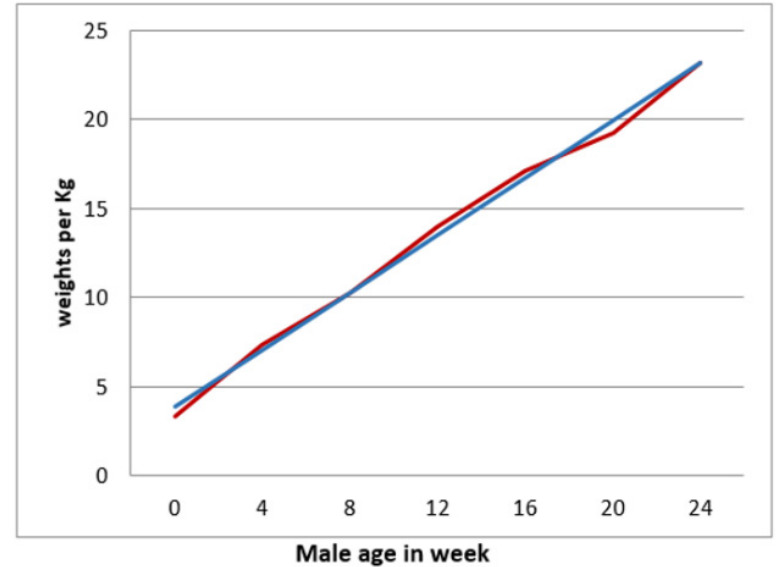

—obseved weights

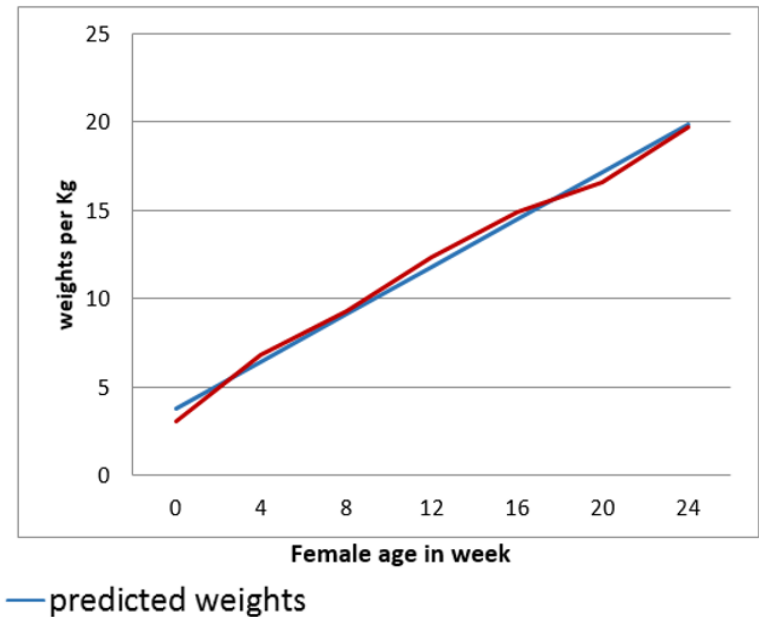

— predicted weights

Figure 2. Observed weights versus the predicted weights by linear equation in Aradi kids. 


\subsection{Morphological Characterization}

Aradi goats are dominate in northern of Saudi Arabia. The color is generally black or black with white spots around eyes nose and mouth. The face of Aradi Goat is Clean-cut with prominent bulging eyes and without beard. The body is long and barrel with straight and medium to short. The tail of Aradi is short curled upwards. The Aradi Goat has a medium-sized with integrated body. The coat of body is long rough hair and bristles. Horns are present in both sexes, which is semi-circular, bent backward in females, and may be helical in males, and long pendulous ears with Black dotted by white color.

Average body weights at 12 weeks were 13.96 and $12.34 \mathrm{Kg}$ in male and female, respectively. Male and female kids had a least square mean 24-week weaning weight of 23.19 and $19.66 \mathrm{~kg}$ as shown in table 6 with the rest of body measurements according to Ediberto et al. (2011). As presented in Table 6, the height at withers for male (0.68) and female (0.62) was lower than reported by Bhattacharya (1989) because he did that measurement at older age (4-year) instead of 24 weeks in the present study. Also, the length of body is less than reported by Bhattacharya (1989).

Table 5. The Intercept $a$ (initial body weight) and regression coefficient b (growth rate /per week) of regression analysis of weight on time per (week) for male and female.

\begin{tabular}{lllll}
\hline \multirow{2}{*}{ Parameter } & \multicolumn{2}{l}{ Male } & \multicolumn{2}{c}{ Female } \\
\cline { 2 - 5 } & Value & $\mathrm{P}$ & Value & $\mathrm{P}$ \\
\hline $\boldsymbol{a}$ & $3.84 \pm 0.33$ & 0.0001 & $3.76 \pm 0.36$ & 0.0001 \\
$\boldsymbol{b}$ & $0.80 \pm 0.02$ & 0.0000 & $0.67 \pm 0.03$ & 0.0000 \\
\hline
\end{tabular}

Table 6. Some phenotypic characterization of pure Aradi

\begin{tabular}{lll}
\hline Trait & Male & Female \\
\hline Height (meter) & $0.68 \pm 0.01$ & $0.62 \pm 0.01$ \\
Length (meter) & $0.86 \pm 0.02$ & $0.80 \pm 0.01$ \\
Depth (meter) & $0.34 \pm 0.01$ & $0.30 \pm 0.01$ \\
Width (meter) & $0.21 \pm 0.01$ & $0.19 \pm 0.01$ \\
Birth weight (kilogram) & $3.36 \pm 0.06$ & $3.06 \pm 0.07$ \\
Weight at 12 week (kg) & $13.96 \pm 0.38$ & $12.34 \pm 0.47$ \\
Weight at weaning, 24 week (kg) & $23.19 \pm 0.63$ & $19.66 \pm 0.61$ \\
\hline
\end{tabular}

\subsection{Molecular Characterization}

Characterization of the 29 markers used in this study showed in Table 7, the maximum allelic numbers were found in loci CSRD247 and RM088 with 13 alleles. On the other hand, ILSTS022, ILSTS033, ILSTS030, ILSTS044, OARE129 loci showed the lowest alleles number 3 in each.

Observed heterozygosity, expected heterozygosity, represented in table 7. From the table, we can observe that observed heterozygosity values were lower than the expected one for ILSTS087, INRA023, TGLA53, SRCRSP8, CSRD247, RM088, ILSTS049, ILSTS002, BM1818, ILSTS034 and ILSTS033 loci, while it was higher than expected heterozygosity for the rest of markers. The average of observed heterozygosity was 0.63 ranged 0.89 in BM2113 locus to 0.17 in ILSTS002 locus. The heterozygosity level of each microsatellite marker varies from locus to another, the heterozygosity and number of alleles determine its polymorphic information content. The average PIC values $(0.61)$ of the selected markers showed its benefits to study the genetic variability in goats.

As mentioned by Barker (1994) in the diversity studies the minimum allele number per each locus must be four in order to reducing the standard error for genetic distances, which reached in most used loci in the present study. Which were in agreement with Tekezaki and Nei (1996) which determined the range of usefulness markers to be used to estimate the genetic variation to be from 0.3 up to 0.8 .

Also, this results are in agreement with that found by Dixit et al., (2012), in a similar study in 22 Indian goats, which found that the genetic diversity ranged from 0.61 in Osmanabadi up to 0.73 in Sirohi. 
Table 6. Allelic number, Heterozygosity (observed and expected) and size range for studied markers

\begin{tabular}{|c|c|c|c|c|c|}
\hline LOCUS & Allelic Number & $\mathbf{H}_{0}$ & $\mathbf{H}_{\mathrm{e}}$ & PIC & Size Range \\
\hline MAF70 & 12 & 0.76 & 0.83 & 0.73 & $129-163$ \\
\hline ILSTS087 & 8 & 0.70 & 0.63 & 0.65 & $150-166$ \\
\hline SRCRSP5 & 7 & 0.79 & 0.80 & 0.75 & $161-178$ \\
\hline SRCRSP1 & 5 & 0.61 & 0.70 & 0.53 & $132-142$ \\
\hline INRA023 & 7 & 0.80 & 0.61 & 0.77 & $190-206$ \\
\hline TGLA53 & 8 & 0.61 & 0.57 & 0.58 & $129-147$ \\
\hline OARFCB48 & 8 & 0.76 & 0.82 & 0.73 & $155-169$ \\
\hline SRCRSP8 & 10 & 0.75 & 0.74 & 0.72 & $203-232$ \\
\hline BM2113 & 10 & 0.81 & 0.89 & 0.79 & $125-150$ \\
\hline CSRD247 & 13 & 0.85 & 0.63 & 0.84 & $225-253$ \\
\hline ILSTS058 & 11 & 0.60 & 0.70 & 0.58 & $134-156$ \\
\hline RM088 & 13 & 0.87 & 0.61 & 0.85 & $106-132$ \\
\hline ILSTS005 & 5 & 0.61 & 0.72 & 0.54 & $190-198$ \\
\hline ILSTS049 & 5 & 0.59 & 0.33 & 0.53 & $165-187$ \\
\hline ILSTS002 & 7 & 0.52 & 0.17 & 0.49 & $117-135$ \\
\hline ILSTS082 & 6 & 0.59 & 0.64 & 0.54 & $118-138$ \\
\hline INRA005 & 6 & 0.76 & 0.82 & 0.72 & $110-122$ \\
\hline SRCRSP9 & 7 & 0.72 & 0.73 & 0.68 & $120-140$ \\
\hline BM1818 & 8 & 0.81 & 0.78 & 0.79 & $243-257$ \\
\hline OARCP34 & 5 & 0.71 & 0.76 & 0.66 & $106-118$ \\
\hline ILSTS029 & 11 & 0.72 & 0.74 & 0.68 & $147-175$ \\
\hline ILSTS019 & 6 & 0.71 & 0.73 & 0.67 & $151-161$ \\
\hline ILSTS034 & 7 & 0.57 & 0.52 & 0.52 & $164-184$ \\
\hline ILSTS022 & 3 & 0.26 & 0.30 & 0.24 & $191-195$ \\
\hline ILSTS033 & 3 & 0.49 & 0.46 & 0.44 & $160-164$ \\
\hline ILSTS030 & 3 & 0.63 & 0.68 & 0.56 & $166-181$ \\
\hline ILSTS044 & 3 & 0.66 & 0.72 & 0.58 & $150-166$ \\
\hline ILSTS011 & 4 & 0.33 & 0.41 & 0.41 & $268-276$ \\
\hline OARE129 & 3 & 0.25 & 0.28 & 0.22 & $151-155$ \\
\hline Average & 7.03 & 0.65 & 0.63 & 0.61 & \\
\hline
\end{tabular}

The expected heterozygosity reached the maximum value in locus RM088 and the minimum one in locus OARE129, the average value was 0.65 . The observed heterozygosity in this study was lower than the average $(0.75)$ of the selected markers as presented in table 2 . The difference between observed heterozygosity in this study and in reference may be due to the two loci OARE129 and ILSTS002 which showed low values of observed heterozygosity 0.28 and 0.17 , respectively. By the other way, the average of expected heterozygosity as reported in table 2 was 0.66 are in agreement with that in the present study (0.65). Among the 29 studied loci, 24 markers showed high polymorphism, number of alleles ranged between four (ILSTS011) and 13 (CSRD247, RM088), while the other five loci had less than four alleles. As suggested by Barker (1994) each microsatellite markers used must have more than three alleles in order to reduce standard errors estimates.

The average of observed allelic number was 9.89 as reported by Iamartino et al. (2005) using 18 markers in Italian goat populations and 9.87 as reported by Glowatzki-Mullis et al. (2006) in 11 Switzerland goat breeds. By the other way, the number was reduced to 6.90 in Chinese goat breeds as reported by ( $\mathrm{Li}$ et al., 2002) and 5.37 in Indian goat breeds as reported by Ganai and Yadav (2001).

Polymorphic information content (PIC) is a statistical measure to know the informativeness of a marker. Aggarwal et al. (2007), studied the Polymorphic information content in three populations Zalawadi, Gohilwadi and Surti the mean PIC values were 0.56, 0.64 and 0.60, respectively. Also, as reported by Botstein et al. (1980) Polymorphic information content values for any loci 0.5 or above is useful in the analysis of population genetic.

\section{Conclusion}

Primary investigation on function show that the linear equation was preferable one than the rest according to easy compute and have only two linear additive parameters which have biological interpretation. The accuracy $\left(\mathrm{R}^{2}\right)$ of that equation was very high ranged between 0.996 and 0.993 for predict weights in male and female, respectively. 
Since, the predicted of future weights well be done accurately, the selection will be efficiency in kids. Aradi goats have a shape sets it apart from the rest of the other local breeds, which is the firmer dynasties in Saudi Arabia. Out of 29 microsatellites studied, the average of observed heterozygosity was 0.63 ranged from 0.89 in BM2113 locus to 0.17 in ILSTS002 locus. The expected heterozygosity reached the maximum value in locus RM088 and the minimum one in locus OARE129, the average value was 0.65 . The polymorphic information content (PIC) values ranged from 0.85 (RM088) to 0.22 (OARE129). Thus, the investigation on a set at 29 microsatellites revealed high degree of genetic variability in Aradi goat indicating an important indigenous genetic resource.

\section{Acknowledgment}

This study was funded by, King Abdul-Aziz City of Science and Technology, Kingdom of Saudi Arabia, Project Number 08-BIO-28-9; and Deanship of Scientific Research, Qassim University, Saudi Arabia, Project Number SR-D-014-2315.

\section{References}

Adeyinka, I. A., \& Mohammed, I. D. (2006). Relationship of live weight and linear body measurement in two breed of Goat of Northern Nigeria. J. of Animal and Veterinary Advances, 5(11), 891-893. Retrieved from http://medwelljournals.com/abstract/?doi=javaa.2006.891.893

Aggarwal, R. A. K., Dixit, S. P., Verma, N. K., Ahlawat, S. P. S., Kumar, Y., Kumar, S., Chander, R., \& Singh, K. P. (2007). Population genetics analysis of Mehsana goat based on microsatellite markers. Current Science, 92, 1133-1137.

Araújo, A. M., Guimarães, S. E. F., Machado, T. M. M., Lopes, P.S., Pereira, C.S., da Silva, F.L., Rodrigues, M.T., Columbiano, V., \& Fonseca, C.G. (2006). Genetic diversity between herds of Alpine and Saanen dairy goats and the naturalized Brazilian Moxotó breed. Genetics and Molecular Biology, 29(1), 67-74. http://dx.doi.org/10.1590/S1415-47572006000100014

Barker, J. S. F. (1994). A global protocol for determining genetic distances among domestic livestock breeds. In Proceeding of the 5th World Congress on genetics Applied to livestock production, 7-12 August, University of Guelph, Ontario, 21, 501-508.

Belkhir, K., Borsa, P., Chikhi, L., Raufaste, N., \& Bonhomme, F. (2004). GENETIX 4.05, logiciel sous Windows TM pour la génétique des populations. Laboratoire Génome, Populations, Interactions, CNRS UMR 5000, Université de Montpellier II, Montpellier (France).

Bertalanffy, L. V. (1957). Quantitative laws in metabolism and growth. The Quarterly Review of Biology, 32, 218-230. http://dx.doi.org/10.1086/401873

Bhattacharya, A. N. (1989). Characteristics of Ardhi Goat in Saudi Arabia. Small Ruminant Research, 2, 217-224. http://dx.doi.org/10.1016/0921-4488(89)90002-3

Botstein, D., White, R. L., Skolnick, M., \& Davis, R. W. (1980). Construction of a genetic linkage map in man using restriction fragment length polymorphism. The American Journal of Human Genetics, 32, 324-331.

Brody, S. (1945). Bioenergetics and Growth. Reinhold, New York, pp1023.

Dixit, S. P., Verma, N. K., Aggarwal, R. A. K., Vyas, M. K., Rana, J., \& Sharma, A. (2012). Genetic diversity and relationship among Indian goat breeds based on microsatellite markers. Small Ruminant Research, 105, 3845. http://dx.doi.org/10.1016/j.smallrumres.2011.11.026

Dixit, S. P., Verma, N. K., Aggarwal, R. A. K., Vyas, M. K., Rana, J., Sharma, A., Tyagi, P., Arya, P., \& Ulmek, B. R. (2010). Genetic diversity and relationship among southern Indian goat breeds based on microsatellite markers. Small Ruminant Research, 91, 153-159. http://dx.doi.org/10.1016/j.smallrumres.2010.02.015

Ganai, N. A., \& Yadav, B. R. (2001). Genetic variation within and among three Indian breeds of goat using heterologous microsatellite markers. Animal Biotechnology, 12, 121-136. http://dx.doi.org/10.1081/ABIO $-100108338$

Glowatzki-Mullis, M. L., Muntwyler, J., \& Gaillard, C. (2006). Cost effective parentage verification with 17-plex PCR for goats and 19-plex PCR for sheep. Animal Genetics, 38, 81-91. http://dx.doi.org/10.1111/j.1365 $-2052.2006 .01550 . x$

Grizzle, J. E., \& Allen D. M. (1969). Analysis of growth and dose response curve. Biometrices, 15, 98-120.

Grossman, M., \& Koops W. J. (1988). Multiphase analysis of lactation curves in cattle. J. Dairy Science, 71, 1598-1608. http://dx.doi.org/10.3168/jds.S0022-0302(88)79723-4 
Hoda, A., Hyka, G. A, Dunner, S., Obexer-Ruff, G., \& Econogene, C. (2011). Genetic Diversity of Albanian Goat Breeds Based on Microsatellite Markers. Archivos de Zootecnia, 60(231), 607-615. http://dx.doi.org/ $10.4321 / \mathrm{S} 0004-05922011000300049$

Iamartino, D., Bruzzone, A., Lanza, A., Blasi, M., \& Pilla, F. (2005). Genetic diversity of Southern Italian goat populations assessed by microsatellite markers. Small Ruminant Research, 57, 249-255. http://dx.doi.org/10. 1016/j.smallrumres.2004.08.003

Kamidi, R. E. (2005). A parametric measure of lactation persistency in dairy cattle. Livestock Production Science, 96, 141-148. http://dx.doi.org/10.1016/j.livprodsci.2004.11.042

Kumar, D., Dixit, S. P., Sharma, R., Pandey, A. K., Sirohi, G., Patel, A. K., ... Ahlawat, S. P. S. (2005). Population structure, genetic variation and management of Marwari goats. Small Ruminant Research, 59, 41-48. http://dx.doi.org/10.1016/j.smallrumres.2004.11.013

Kumar, S., Dixit, S. P., Verma, N. K., Singh, D. K., Pande, A., Kumar, S., ... Singh, L.B. (2009). Genetic Diversity Analysis of the Gohilwari Breed of Indian Goat (Capra hircus) Using Microsatellite Markers. American Journal of Animal and Veterinary Sciences, 4(3), 49-57. http://dx.doi.org/10.3844/ajavsp.2009.49.57

Khalil, M. H., Mohamed, K. M., Al-Saef, A. M., Zeitoun, M. M. and El-Zarei, M. F. (2010). Crossbreeding components for growth, carcass and meat composition traits in crossing Saudi Aradi with Damascus goats. Small Ruminant Research, 94(1): 10-16. http://dx.doi.org/10.1016/j.smallrumres.2010.05.020

Leech, F. B., \& Healy, M. J. R. (1959). The analysis of experiments on growth rate. Biometrices, 15, 264-278.

Li, M. H., Zhao, S., Bian, C., Wanga, H., Wei, H., Liu, B., ... Li, K. (2002). Genetic relationships among twelve Chinese indigenous goat populations based on microsatellite analysis. Genetic Selection Evolution, 34, 729 744. http://dx.doi.org/10.1051/gse:2002032

Macciotta, N. P., Dimauro, C., Rassu, S. P, Steri, R., \& Pulina, G. (2011). The mathematical description of lactation curves in dairy cattle. Italian Journal of Animal Science, 10, 213-223. http://dx.doi.org/10.4081/ijas. 2011.e51

Madalena, F. E., Martinez, H. L., \& Freltas, A. F. (1979). Lactation curves of Holstein in Friesian and Holstein-Friesian X Gir cows. Animal science, 29, 101-107. https://doi.org/10.1017/S0003356100012198

Morant, S. V., \& Gnanasakthy, A. (1989). A new approach to the mathematical formulation of lactation curves. Animal science, 49, 151-162. https://doi.org/10.1017/S000335610003227X

Mostert, B. E., Theron H. E., \& Kanfer, F. H. J. (2003). Derivation of standard lactation curves for South African dairy cows. South African Journal of Animal Science, 33, 70-77.

Mousa, E. (1989). Genetic and phenotypic variation in lambs' growth. M.Sc. Thesis in Animal breeding, Assuit University, Faculty of Agriculture, Department of Animal production, Assuit, Egypt.

Mousa, E., Al-Saef, A. M., El-Zarei, M. F., Mohamed, K. M., \& Khalil, M. H., (2013a). A parametric Modeling of Growth Curve on Goat kids in Saudi Arabia. Journal of Agricultural and Veterinary Sciences, Qassim University, 6(2), 133-146.

Mousa, E., Monzaly, H., Shaat, I., \& Ashmawy, A. (2013b). Factors affecting birth and weaning weights of native Farafra lambs in Upper Egypt. Egyptian Journal of Sheep and Goat Sciences, 8(2), 1-10.

Mousa, E., Sahaat, M. A., \& Melak, S.A. (2010). Phenotypic and genetic variation in lambs' growth using linear models. Egyptian Journal of Sheep and Goat Sciences, 5(2), 23-35

Nagy, S., Poczai, P., Cernák, I., Gorji, A. M., Hegedűs, G., \& Taller, J. (2012). PICcalc: an online program to calculate polymorphic information content for molecular genetic studies. Biochemical Genetics, 50(9-10), 670-672. http://dx.doi.org/10.1007/s10528-012-9509-1

Nelder, J. A. (1961). The fitting of generalization of the logistic curve. Biometrics, 17, 89-98. http://dx.doi.org/10. $2307 / 2527498$

Richards, J. F. (1959). A flexible growth function for empirical use. Journal of Experimental Botany, 10, 290-300. https://doi.org/10.1093/jxb/10.2.290

Riva, J., Rizzi, R., Marelli S., \& Cavalchini, L. G. (2004). Body measurements in Bergamasca sheep. Small Ruminant Research, 55, 221-227. http://dx.doi.org/10.1016/j.smallrumres.2003.12.010 
Saitbekova, N., Gaillard, C., Obexer-Ruff, G., \& Dolf, G. (1999). Genetic diversity in Swiss goat breeds on microsatellite analysis. Animal Genetics, 30, 36-41. http://dx.doi.org/10.1046/j.1365-2052.1999.00429.x

Seilsuth, S., Seo, J. H., Kong, H. S., \& Jeon, G. J. (2016). Microsatellite Analysis of the Genetic Diversity and Population Structure in Dairy Goats in Thailand. Asian-Australasian Journal of Animal Sciences, 29(3), 327-332. https://doi.org/10.5713/ajas.15.0270

Shadma, F., Bhonga, C. D., Ranka, D. N., \& Joshi, C. G. (2008). Genetic variability and bottleneck studies in Zalawadi, Gohilwadi and Surti goat breeds of Gujarat (India) using microsatellites. Small Ruminant Research, 77, 58-64. http://dx.doi.org/10.1016/j.smallrumres.2008.01.009

Sprint, P. (1967). Estimation of mean growth curve for groups of organisms. Journal of Theoretical Biology, 17, 159-166. http://dx.doi.org/10.1016/0022-5193(67)90026-4

Tekezaki, N., \& Nei, N. (1996). Genetic distances and reconstruction of phylogenetic trees from microsatellite. Genetics, 144, 389-399.

Wilson, P. N. (1958). The effect of plane of nutrition on growth and development of the East African desert goat. 1. Effect of plane of nutrition on live weight gain and external measurements of kids. J. Agriculture Science, 50, 198-210.

Wilson, R. T. (1976). Studies on the livestock of Southern Darfur, Sudan. IV. Production traits in goats. Tropical Animal Health and Production, 8, 221-232.

Winsor, C. P. (1932). The Gompertz curve as a growth curve. Proc. National Academy of science, 18, 1-16.

\section{Copyrights}

Copyright for this article is retained by the author(s), with first publication rights granted to the journal.

This is an open-access article distributed under the terms and conditions of the Creative Commons Attribution license (http://creativecommons.org/licenses/by/4.0/). 